\title{
FORMULATION AND EVALUATION OF ALPHA ARBUTIN SKIN LIGHTENING CREAM USING POLYACRYLATE BASE BY COLD PROCESS
}

\author{
RESMI MUSTARICHIE ${ }^{a^{*}}$, DOLIH GOZALIb \\ aDepartment of Pharmaceutical Analysis and Medicinal Chemistry, Faculty of Pharmacy, Universitas Padjadjaran, Indonesia, bDepartment \\ of Pharmaceutics, Faculty of Pharmacy, Universitas Padjadjaran, Indonesia \\ Email: resmi.mustarichie@unpad.ac.id \\ Received: 29 Aug 2018, Revised and Accepted: 19 Nov 2018
}

\begin{abstract}
Objective: The objective of this research was to formulate and evaluate alpha arbutin skin lightening cream using polyacrylate base by cold process.

Methods: Five formulas of alpha arbutin skin lightening cream were prepared with Polyacrylate Base with different polyacrylate concentrations as a cream base for each formula. The various concentrations of polyacrylate $(2,3,4,5$, and $6 \%)$ was used as a cream base. The resulting preparation was then examined and observed for consistency, color, odor, and stability for $28 \mathrm{~d}$ of storage.

Results: The phase separation test results stated that the five cream formulas did not experience phase separation in 2500 , 3000 , and 3750 rpm centrifugations so that it could be concluded that the five cream formulas were stable in storage at room temperature for at least 12 mo. From the physical evaluation of cream preparations, it was found that the cream formula with $6 \%$ polyacrylate concentration gave the best stability results.
\end{abstract} Cream safety testing results stated that the cream did not irritate the skin of the wearer.

Conclusion: The results obtained in this research work clearly indicated alpha arbutin cream can be formulated using polyacrylate as a cream base, and in its manufacture, it can be carried out with a cold process.

Keywords: Alpha arbutin, Formulation, Cream, Polyacrylate, Cold process

(C) 2019 The Authors. Published by Innovare Academic Sciences Pvt Ltd. This is an open-access article under the CC BY license (http://creativecommons.org/licenses/by/4.0/) DOI: http://dx.doi.org/10.22159/ijap.2019v11i1.29393

\section{INTRODUCTION}

The skin is a receptor organ that is always associated with the external environment. As you age and environmental influences, your skin will experience aging and decrease in terms of functional and aesthetic. Therefore, skin that is always healthy, white and bright is always the dream and desire of women. Skin color is determined by various factors, but the most important is the content of melanin. Melanin is synthesized in melanocytes where tyrosinase plays an important role in this process. Due to the work of tyrosinase, tyrosine is first converted to 3,4-dihydroxyphenylalanine (DOPA) and then to dopaquinone, which after several transformations is converted to melanin. Tyrosinase is made on the ribosome, transported to the lumen of the coarse endoplasmic reticulum of melanocytes, and collected in vesicles formed in the Golgi zone. Melanin produced can be eumelanin and pheomelanin. Eumelanin is a dark brown pigment produced by specialized cells of the epidermis, namely melanocytes, which are located below or between basal stratum cells and in hair follicles. The pigment found in red hair is called pheomelanin and contains cysteine as part of its structure $[1,2]$. Enlightening of skin color can occur through a decrease in melanin levels with various intermediary processes. Standard dermatologic agent for skin lightening is hydroquinone, but its safety is questionable, leading to the use of alternative agents such as retinoids, mequinol, azelaic acid, kojic acid, oleosin, licorice extract, ascorbic acid, soy proteins, N Aeetyl glucosamine and arbutin. [3]. Alpha arbutin is one of the substances that can brighten the skin. Arbutin is a naturally occurring derivative of hydroquinone. It is believed to be one of the best alternatives to hydroquinone as it provides the skin-lightening effect of hydroquinone without some of the risks. Alpha arbutin works by blocking the biosynthesis of melanin by inhibiting the activity of tyrosinase. The tyrosinase enzyme is activated by forming chelates with vital copper ions and suppresses tautomerization from dopachrome, acting as a reducing agent in melanin intermediates, thus blocking oxidation chain reactions at various points from tyrosine/dopa to melanin. Inhibition of the formation of melanin with alpha arbutin can cause the skin to become brighter without any side effects [4-7]. Skin lightening cream is one form of the cosmetic preparation, is a mixture of chemicals or other ingredients with properties that can bleach black spots (brown) on the skin. The purpose of using it for a long time in order to eliminate or reduce hyperpigmentation of the skin [8]. The cream is a semi-solid dosage form containing one or more dissolved or dispersed medicinal ingredients in an appropriate base material [9]. Cream dosage forms are preferred because they are easily spread evenly, leaving no oily coating and are easily washed. The term cream is widely used in pharmaceutical and cosmetic industries [10]. Lately, the use of fatty acids or long-chain alcohols in solid or wax form for making cream base on cosmetic preparations has been abandoned, because of its poor nature which can cause the formation of blackheads and pore closure on the face. The use of solid-shaped materials or waxes for the manufacture of cream bases began to shift and was replaced with liquid or oil-shaped ingredients that have non-comedogenic properties such as polyacrylate. Rusmadi et. al [11] reported their study on the skin lightening practice and health symptoms among female students in Malaysia and their concluded that the use of skin lightening products was common among female students in this study and some of these products could cause skin problems such as skin peeling, acne, and itching.

This study reports the formulation and evaluation of skin lightening cream with alpha arbutin using polyacrylate base by cold process.

\section{MATERIALS AND METHODS}

\section{Materials}

Alpha arbutin ex. Pentapharm (PT. Baktijala Kencana Citra), C12-15 alkyl benzoate, Polyacrylate (Sodium polyacrylonimethyl taurate and hydrogenated polidecene and trideceth-10), DMDM Hydantoin, Glycerin, Emersion Oil, Methylene blue solution. All ingredients used were of analytical grade.

\section{Methods}

\section{Formulation}

Five formulas of alpha arbutin skin lightening cream were prepared with Polyacrylate Base with different polyacrylate concentrations as a cream base for each formula. The formula was referred to standard cosmetology textbook $[12,13]$. Information about ingredients uses as follows: C12-15 alkyl benzoate was chosen as C12-15 Alkyl Benzoate 
improved the patient's condition by performing the function of lift both skin hydration and skin surface lipids. C12-15 Alkyl benzoate is a mixture of benzoic acid esters that consist of benzoic acid and alcohols that have carbon chain lengths from 12 to 15 . Other long-chain alkyl benzoate ingredients that may be used in cosmetics and personal care products include C16-17 Alkyl Benzoate, Stearyl benzoate, Isostearyl Benzoate, Ethylhexyl benzoate, and Octyldodecyl benzoate. The C1215 Alkyl benzoate and the other long-chain alkyl benzoate ingredients may be used in a wide variety of cosmetic products including baby products, bath products, eye makeup, lipstick, shaving products, suntan products, as well as hair care, nail care, and skin care products $[14,15]$. Polyacrylate acted as a binder, and film-forming, and hair fixative [16]. DMDM hydantoin is an organic compound which belongs to a class of compounds known as hydantoins. It is used in the cosmetics industry and is found in products such as shampoos, hair conditioners, hair gels, Rite Aid Liquid Lubricants, and skin care products. DMDM hydantoin works as a preservative. This substance can cause inflammation of the skin, burns, irritation, and tears. [17].

\section{Formulation testing}

Formulation testing referred to other cream testing carried out by another researcher [18] The formula was then tested including dilution test and color test; Stability testing included organoleptic observation, $\mathrm{pH}$ test, viscosity measurement; Cream Phase Separation Test included centrifugation method, and freeze-thaw cycle method; Preparation safety testing was carried out by patch test method for 10 volunteers by applying cream with alpha arbutin on the back skin of the right hand and cream preparation without alpha arbutin on the back skin of the left hand for $5 \mathrm{~min}$, and observed changes. Tests were carried out in the same place for three consecutive days; Data analysis was performed using a block design statistical method complete with a fixed random sub-sampling model because there were several treatments and blocks in the experiment.

\section{RESULTS AND DISCUSSION}

Formulation: Formula can be seen in table 1.

Table 1: Cream preparation formula

\begin{tabular}{|c|c|c|c|c|c|}
\hline \multirow[t]{2}{*}{ Ingedients } & \multicolumn{5}{|c|}{ Formulation code } \\
\hline & F-1 (g) & F-2 (g) & F-3 (g) & F-4 (g) & F-5 (g) \\
\hline Alpha arbutin & 1 & 1 & 1 & 1 & 1 \\
\hline C 12-15 Alkyl benzoate & 15 & 15 & 15 & 15 & 15 \\
\hline Polyacrylate & 2 & 3 & 4 & 5 & 6 \\
\hline DMDM Hydantoin & 0.3 & 0.3 & 0.3 & 0.3 & 0.3 \\
\hline Aquadest ad & 100 & 100 & 100 & 100 & 100 \\
\hline
\end{tabular}

The formula was prepared by a cold method [19]. Advantages and disadvantages of the cold cream process were reported by Sahu et. al [20]. In some stages, the cold cream process was simple, no need special tools and no need heat energy required. The second half of the nineteenth century saw two advances in cold cream formulations that together enabled them to be manufactured on an industrial scale. The first was the replacement of almond oil by petrolatum and mineral oil; the second, the inclusion of borax (sodium borate) [21]. The formula was made by mixing Polyacrylate and aquadest and stirred using ultra turrax until both are mixed. While stirring constantly, C 12-15 15\% alkyl benzoate was added little by little until a homogeneous cream mass is formed. Then added alpha arbutin which has been dissolved first in $10 \mathrm{ml}$ of distilled water while continuing to stir. The remaining aquadest was added while continuing to stir until the specified mass. Enter $0.3 \%$ DMDM hydantoin (12 drops) and stir until homogeneous. Physical observations, the five formulas were white, had thick, viscous cream and had a distinctive odor. Color in cosmetics played an important role in making creams seem more appealing [22].

\section{Organoleptic observation results}

It was found that the formula did not experience physical changes in color and odor for $28 \mathrm{~d}$ of storage time. But there was a change in the consistency of the cream. Changes appear in F-1 and F-2, while F-3, F-4, and F-5 did not experience changes in consistency. The change in consistency in F-1 occurred on the $14^{\text {th }}$ day, which was a change in consistency from thick to thick easily flowing. While the change in consistency in F-2 occurred on day 21, which was a change in consistency from thick with a higher viscosity quantity to thick, but even so, overall physical/organoleptic stability could be said to be quite reasonable.

\section{pH measurement results}

The results of $\mathrm{pH}$ measurements on storage time can be seen in fig. 1 .

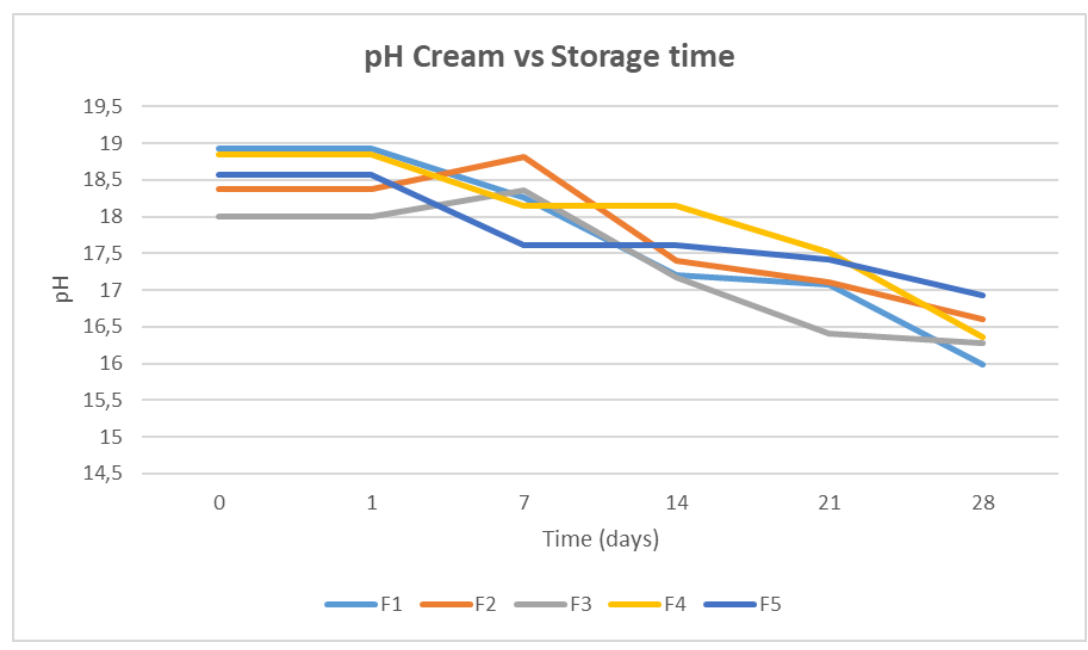

Fig. 1: Measurement of $\mathrm{pH}$ against storage time 
From fig. 1, showed that during storage time, the $\mathrm{pH}$ of the five cream formulas had decreased. Alpha arbutin was stable in the range of $\mathrm{pH}$ 3.5-6.5. After statistical calculations with a complete randomized block design [22] sub-sampling $\mathrm{pH}$ measurement with the fixed method at a significant level $\alpha=0.05$, the result was that the null hypothesis (H0) was rejected, assuming there was no difference in the average treatment effect tested, because of $\mathrm{F}$ count greater than F table. With a 95\% confidence level $(\alpha=0.05)$ it was stated that the cream with various concentrations of polyacrylate had a significantly different $\mathrm{pH}$. From the results of the NewmanKeuls test [24], it was found that the real $\mathrm{pH}$ difference was only seen in F-3 and F-4 for $28 \mathrm{~d}$ of storage time. This difference was probably caused by the carrying of water, there is microbial contamination during storage time, so there will be an increase in acidity. But even so, the $\mathrm{pH}$ values were still included in the $\mathrm{pH}$ range of good preparation for preparations with the aim of topical use, namely 5-7 [25]. Study on the effects on the $\mathrm{pH}$ of human skin of an 0/W emulsion (nonionic self-emulsifying base) with and without vitamin A palmitate, or vitamin E acetate, or ceramide III, using a non-invasive method was reported by Leonardi et al. [26]. On the other hand, investigation of the relationship between the $\mathrm{pH}$ of different primer products, product contents, and appropriateness of product labeling and packaging reported by Woolf and Shaw [27].

\section{Viscosity measurement results}

Observations of viscosity changes to storage time can be seen in fig. 2 .

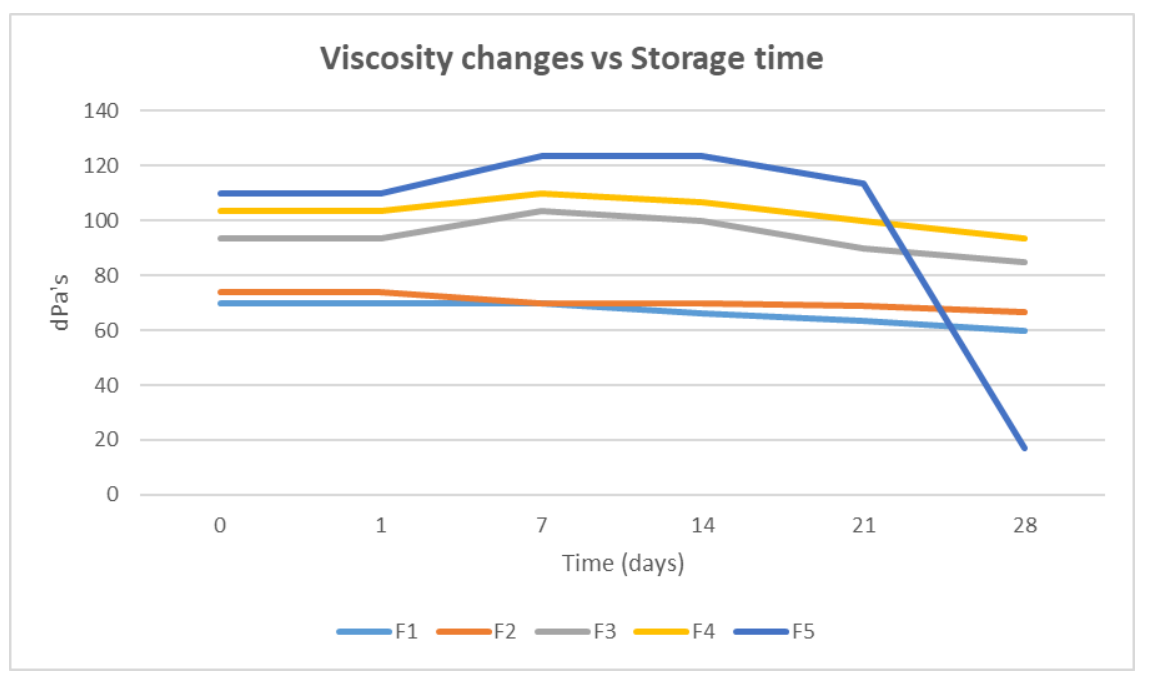

Fig. 2: Viscosity changes against storage time

It is the thumb of rules that some cosmetics must take on a specific viscosity to satisfy customer impressions and research suggestions; cosmetic products marketed "rich" or "luxurious" may have high viscosity while products touted as "light" or "natural" may have low viscosity [28].

From fig. 2 it can be seen that the viscosity of the five cream formulas had changed during $28 \mathrm{~d}$ of storage time. As a rule, when it goes about cosmetics it goes mostly about viscosity because the liquids usually flow easily and they have no signs of elasticity [29]. Viscosity is strongly influenced by the number of emulsifiers in an emulsion. The greater the concentration of polyacrylate added to the formula, the viscosity of the cream preparation will also increase [30]. This could be seen in the initial viscosity of cream making (fig. 2).

According to Lachman [31], the W/O emulsion preparation would usually experience a decrease in viscosity immediately when making because it flocculated rapidly and then was relatively constant, unlike the emulsion of $\mathrm{O} / \mathrm{W}$ which would experience increased viscosity during storage. In this case, the lump of lumps caused an increase in viscosity. Cream preparations had an average increase in viscosity on the $7^{\text {th }}$ day, and then in the following week it decreased, but the cream still had good viscosity. The decrease was thought to be caused by factors that influence during storage, such as changes in room temperature. Increased room temperature could interfere with the durability of the cream, which results in the discharge of the hydrated complex from a polyacrylate, and caused a decrease in the viscosity of the continuous phase (water) and increase the motion of the globul dispersed phase (oil). The reduction in viscosity was caused by a decrease in the viscosity of the continuous phase because of the distance of separation between globules increases. Another factor was repeated stirring at the time of viscosity measurement using a viscometer and spindle rod rotation on the viscometer. At F-2, viscosity appears to continue to decrease. This was allegedly caused by the incompletely mixed polyacrylateforming materials, such as trideceth-10 which functions as an emulgator, hydrogenated polydecene, and sodium polyacrylonylimethyl law. The incomplete mixing of the ingredients caused a decrease in the function of polyacrylate. After statistically calculated using a complete random block design subsampling, the null hypothesis ( $\mathrm{HO}$ ) was rejected, assuming there was no difference in the average treatment effect tested, because $\mathrm{F}$ count was greater than $\mathrm{F}$ table, with a significant level $\alpha=0.05$. This meant that cream preparations with various polyacrylate concentrations had significantly different viscosities. From the results of the calculation of the Newman-Keuls Test, it was concluded that the difference in viscosity of the cream preparation significantly with a $95 \%$ confidence level was found in F-1 and F-3 creams; F-2 and F-3; F-1 and F-4; F-2 and F-4; F-3 and F-4; F-1 and F-5; F-2 and F-5; F-3 and F-5; F-4 and F-5. Juntawong et al. [32] claimed, however, that viscosity of formulation did not change as stirring intensity and mixing temperature was increased. The amount of oil affected viscosity of cream base whereas the stirring intensity and temperature did not affect the viscosity of the cream base prepared from emulsifying polymers.

\section{Determination of emulsion type}

Results of determination of emulsion type confirmed that all formula was $0 / \mathrm{W}$ type.

\section{Results of cream phase separation testing}

Test results by centrifugation method showed in table 2 . The table showed that the five cream formulas did not experience phase separation after centrifugation at speeds of 2500,3000 , and 3750 rpm. 
Table 2: Globul size before and after centrifugation

\begin{tabular}{llll}
\hline Formulation code & \multicolumn{2}{l}{ Globul size $(\boldsymbol{\mu m})$} & \\
\cline { 2 - 4 } & Day-0 & After centrifugation & After centrifugation \\
\cline { 2 - 4 } & & at 2500 rpm & at 3000 rpm \\
\hline F-1 & 8.42541436 & 9.01759530 & 9.63576158 \\
F-2 & 8.27586206 & 9.12650602 & 9.49044586 \\
F-3 & 8.26153846 & 9.71947194 & 9.91803278 \\
F-4 & 8.09523809 & 8.89880952 & 9.02597402 \\
F-5 & 8.02941176 & 8.59331476 & 8.61904761 \\
\hline
\end{tabular}

Notes: Each data was the average result of 3 trials

The use of centrifugation methods in viewing emulsion phase separation is very useful for predicting the storage time of preparation [33]. Stokes's law showed that increasing gravity could accelerate separation. Lachman stated that centrifugation at 3750 rpm within a radius of $10 \mathrm{~cm}$ centrifugation for $5 \mathrm{~h}$ was equivalent to the effect of gravity for approximately one year. Based on the conversion, it was found that the centrifugation with a speed of 2500 rpm for $5 \mathrm{~h}$ was equivalent to the effect of gravity of approximately 8 mo, while for speeds of $3000 \mathrm{rpm}$ the equivalent effect of gravity was approximately 10 mo. Measurement of globul particles could be used to evaluate the emulsion, which was to analyze the stability changes that occur in cream preparations. The increased size of globules resulted in the easier integration of globul-globules into the phase and finally separated from the continuous phase. The occurrence of phase separation indicates instability in the preparation. Based on the results of the centrifugation, it could be concluded that the five cream formulas had a minimum shelf life of 12 mo. This meant that the five cream formulas were stable against gravity during 12 mo of storage time. Based on the calculation of statistical data, the null hypothesis ( $\mathrm{H} 0)$ was rejected, assuming there was no difference in the average treatment effect tested, because Fcount was greater than Ftable, with a significant level of $\alpha$ $=0.05$. It meant that cream preparations with various polyacrylate concentrations had significantly different globule sizes. From the results of the calculation of the Newman-Keuls Test, it was concluded that the difference in the size of the cream preparation globule significantly with a 95\% confidence level was found in F-5 and F-4 creams; F-5 and F-1; F-5 and F-2; F-5 and F-3; F-4 and F-3. The test carried out on this globule was guided by other researchers $[34,35]$

\section{Test results with the freeze-thaw cycle method}

Freeze-thaw cycle testing was a part of stability testing that allows you to determine if your product would remain stable under various conditions [36]. In this study, it was carried out by storing cream preparations on the freeze-thaw cycle at two different temperatures, namely $4{ }^{\circ} \mathrm{C}$ and $45{ }^{\circ} \mathrm{C}$. This method was done to see the physical stability of the cream after being stored for thirty days of storage in the freeze-thaw cycle. Storage is carried out in several cycles, and one cycle lasts for three days at each temperature. $0.2 \mathrm{~g}$ weighed cream is put into several vials and stored in a refrigerator $\left(4^{\circ} \mathrm{C}\right.$ temperature) for three days, then continued by storing the preparation in the oven (temperature $45^{\circ} \mathrm{C}$ ) at the same time. Characteristics of the physical stability of the cream observed were changes in particle size. Particle measurements were carried out using a microscope [31]. Table 3 shows the results of globul cream measurement on day zero and day thirty storage at room temperature.

Table 3: Results of the measurement of cream globul size at room temperature

\begin{tabular}{lll}
\hline Formulation code & Globul size $(\boldsymbol{\mu m})$ & \\
\cline { 2 - 3 } & Day-0 & Day-30 \\
\hline F-1 & 8.425414365 & 8.479623824 \\
F-2 & 8.275862069 & 8.280254777 \\
F-3 & 8.261538462 & 8.322580645 \\
F-4 & 8.095238095 & 8.114754098 \\
F-5 & 8.029411765 & 8.069620253 \\
\hline
\end{tabular}

Notes: Each data was the average result of 3 trials

It was found that there was no separation of cream on the five formulas after storage in the Thaw Freeze cycle and an increase in the size of the globul dispersed phase after experiencing the Thaw Freeze cycle compared to room temperature. The results of the calculation of the Newman-Keuls Test concluded that the difference in the size of the cream globule size significantly with a $95 \%$ confidence level was found in F-5 and F-1 creams. The Freeze-thaw cycle method was applied by Tozetto et al. [37] at their research on the formulation of the extract of Punica granatum.

Each globul size data in table 2 and table 3 was obtained using the method in table 4 . In table 4 , was a calculation example for F-1 on day-0, it turned out that the average diameter for F-1 was 8.425414365 , but in table 2, we omitted the last digit.

Table 4: Day-0 globul measurement for formula 1 (F-1)

\begin{tabular}{|c|c|c|c|c|c|c|c|}
\hline \multirow[t]{2}{*}{ Size range } & \multirow[t]{2}{*}{$\mathbf{d}$} & \multicolumn{3}{|l|}{$\mathbf{n}$} & \multicolumn{3}{|l|}{ nd } \\
\hline & & I & II & III & I & II & III \\
\hline $0-10$ & 5 & 310 & 310 & 310 & 1550 & 1550 & 1550 \\
\hline $10-20$ & 15 & 26 & 26 & 26 & 390 & 390 & 390 \\
\hline $20-30$ & 25 & 13 & 13 & 13 & 325 & 325 & 325 \\
\hline $30-40$ & 35 & 6 & 6 & 6 & 210 & 210 & 210 \\
\hline $40-50$ & 45 & 0 & 0 & 0 & 0 & 0 & 0 \\
\hline $50-60$ & 55 & 1 & 1 & 1 & 55 & 55 & 55 \\
\hline $60-70$ & 65 & 0 & 0 & 0 & 0 & 0 & 0 \\
\hline $70-80$ & 75 & 1 & 1 & 1 & 75 & 75 & 75 \\
\hline $80-90$ & 85 & 3 & 3 & 3 & 255 & 255 & 255 \\
\hline $90-100$ & 95 & 2 & 2 & 2 & 190 & 190 & 190 \\
\hline \multirow[t]{3}{*}{ Total } & $\Sigma$ & 362 & 362 & 362 & 3050 & 3050 & 3050 \\
\hline & \multicolumn{4}{|c|}{ Globul Diameter $\left(\sum n d / \sum n\right)$} & 8.425414365 & 8.425414365 & 8.425414365 \\
\hline & \multicolumn{4}{|c|}{ Average Diameter } & 8.425414365 & & \\
\hline
\end{tabular}




\section{Safety test results in the alpha arbutin skin lightening cream}

Preparation safety testing was carried out by patch test method for 10 volunteers by applying cream with alpha arbutin on the back skin of the right hand and cream preparation without alpha arbutin on the back skin of the left hand for $5 \mathrm{~min}$, and observed changes. Tests were carried out in the same place for three consecutive days. Cream preparations tested were the most stable cream preparations during stability testing. Based on observational data, it was found that the alpha arbutin cream preparation with $6 \%$ polyacrylate base did not irritate the skin. This result was evidenced by the absence of irritation, burning, itching or pain on the skin of the volunteer. The same results also occur in cream preparations without alpha arbutin. This was because the ingredients used in formulas were synthetic ingredients that had been proven safe, inert, non-irritating, colorless, tasteless, and had a good sense of touch. However, Rusmadi et al. [11] in their study on the Skin Lightening Practice and Health Symptoms among Female Students in Malaysia, concluded the use of skin lightening products was common among female students and some of these products could cause skin problems such as skin peeling, acne, and itching.

\section{CONCLUSION}

Alpha arbutin as an active ingredient that has an effect on skin color enlightenment can be formulated in cream dosage forms using polyacrylate as a cream base, and in its manufacture, it can be carried out by a cold process. Alpha arbutin skin lightening cream preparations based on polyacrylate at concentrations of $2,3,4,5$, $6 \%$ had a stable consistency, color, and odor, except for $\mathrm{pH}$ and viscosity which decreased in storage. It was found that the five formulas made had physical stability and would have a minimum storage time of 12 mo. Alpha arbutin skin lightening cream with $6 \%$ polyacrylate base had the best physical stability.

\section{ACKNOWLEDGMENT}

We thank Rina Triana for technical support.

\section{AUTHORS CONTRIBUTIONS}

All the authors have contributed equally

\section{CONFLICT OF INTERESTS}

There is no conflict of interest between authors

\section{REFERENCES}

1. Mescher AL. Junqueira's basic histology: text and atlas. Fourteenth edition. New York: McGraw-Hill Education; 2007.

2. Junqueira CL, Carneiro J. Basic histology (Indonesian: Histologi Dasar). 10th Ed. Translated by Dr. Jan Tambayong. Jakarta: Penerbit Buku Kedokteran EGC; 2007. p. 357-64.

3. Mukul S, Surabhi K, Atu N. Cosmeceuticals for the skin: an overview. Asian J Pharm Clin Res 2011;4:1-6.

4. Webster I. What is Arbutin? Available from: https://www.dermastore.co.za/what-is-arbutin. [Last accessed on 26 Aug 2018]

5. Sandberg S. Alpha-arbutin-is it a safe alternative to hydroquinone? 2013. Available from: https://bestfadecreams.com/alpha-arbutinsafe-alternative/ [Last accessed on 26 Aug 2018]

6. Ochi E. Get to know alpha arbutin, the content of beauty products that are safe to brighten the face; 2018. Available from: https://journal.sociolla.com/beauty/mengenal-alphaarbutin/. [Last accessed on 26 Aug 2018]

7. Sugimoto KS, Nishimura T, Nomura K, Sugimoto K, Kuriki T. Inhibitory effects of $\alpha$-arbutin on melanin synthesis in cultured human melanoma cells and a three-dimensional human skin model. Biol Pharm Bull 2004;27:510-4.

8. Cherney K. 8 treatment options for hyperpigmentation; 2018. Available from: https://www.healthline.com/health/beautyskin-care/hyperpigmentation-treatment. [Last accessed on 26 Aug 2018]

9. Indonesian Pharmacopeia (Indonesian: Farmakope Indonesia). $4^{\text {th }}$ Ed. Jakarta: Departemen Kesehatan RI; 1995. p. 6.

10. Allen LV, Ansel HC. Ansel's pharmaceutical drug forms and drug delivery system. 10 $0^{\text {th }}$ Ed. Walters Kluwer: Section IV; 2014.
11. Niazi SK. Handbook of pharmaceutical manufacturing formulations. Vol. 4. CRC Press; chapter 8 Guidance on Formulating semisolid drugs; 2004.

12. Rusmadi SZ, Ismail SNS, Praveena SM. Preliminary study on the skin lightening practice and health symptoms among female students in Malaysia. J Environ Public Health 2015. http://dx.doi.org/10.1155/2015/591790

13. Harry RG. Harry's cosmetology, New York: Chemical Publishing Co; 1973. p. 594-8.

14. Cosmetics Info. C12-15 Alkyl benzoate. Available from: https://cosmeticsinfo.org/ingredient/c12-15-alkyl-benzoate. [Last accessed on 12 Mar 2018]

15. Raposo S, Salgado A, Gonçalves L, Pinto PC, Urbano M, Ribeiro HM. Safety assessment and biological effects of a new cold processed SilEmulsion for a dermatological purpose. Biomed Res Int 2013. Doi:10.1155/2013/181634

16. DepKes RI Indonesian Cosmetics Codex. (Indonesian: Kodeks kosmetika Indonesia), ed isi II, Vol. II; 1997. p. 33.

17. Dmdm Hydantoin. Available http://www.sumberberliankimia.com/product/dmdmhydantoin-p313132.aspx [Last accessed on 16 Jan 2018]

18. Wulandari P. Stability test of physical and chemical cream ethanol extracts fern (Nephrolepis falcata (Cav) C. Chr), thesis. Jakarta, Indonesia: National Islamic University of Syarif Hidayatullah; 2016.

19. Preparation of cold cream. Available from: https://labmonk.com/preparation-of-cold-cream [Last accessed on Aug 2018]

20. Sahu T, Patel T, Sahu S, Gidwani B. Skin cream as topical drug delivery system: a review. J Pharm Biol Sci 2016;4:149-54.

21. Bennett J. Cosmetics and Skin; 2018. Available from: https://cosmeticsandskin.com/index.php. [Last accessed on Aug 2018]

22. Novakovich J. A guide to color additives in cosmetics. Available from: https://theecowell.com/blogs/well/color-additives-incosmetics. [Last accessed on 28 Aug 2018]

23. Stat Trek. Experimental design. Available from: https://stattrek.com/experiments/experimental-design.aspx. [Last accessed on Aug 2018]

24. De Muth JE. Basic statistics and pharmaceutical statistical applications. 2nd ed. Boca Raton FL. Chapman and Hall/CRC; 2006. p. 229-59.

25. Trench BLP. Do pH levels in beauty products really matter? Available from: https://www.refinery29.com/ph-levels-inbeauty-products. [Last accessed on 28 Aug 2018]

26. Leonardi GR, Gaspar LR, Maia Campos PMBG. Study of pH variation on the skin using cosmetic formulation $\mathrm{s}$ with and without vitamins A, E or ceramide: by a non-invasive method, An Bras Dermatol; 2002. p. 77.

27. Woolf $A D$, Shaw JS. Nail primer cosmetics: correlations between product $\mathrm{pH}$ and adequacy of labeling. J Toxicol Clin Toxicol 1999;37:827-32.

28. Mixer Direct. How to measure the viscosity of cosmetics. Available from: http://blog.mixerdirect.com/how-to-measurethe-viscosity-of-cosmetics. [Last accessed on 28 Aug 2018]

29. PCE Instruments. Viscometer in Cosmetics. Available from: https://www.pce-instruments.com/f/english/media/viscometercosmetics.pdf. [Last accessed on 28 Aug 2018]

30. Maqbool A, Mishra MK, Pathak S, Kesharwani A, Kesharwani A. Semisolid dosage forms manufacturing: tools, critical process parameters, strategies, optimization, and recent advances. Indo Am J Pharm Res 2017;7:882-93.

31. Lachman L, Lieberman HA, Kanig JL. The theory and practice industrial pharmacy. $4^{\text {th }}$ Ed. India: CBS Publishers and Distributor Pvt Ltd. e-book; 2016.

32. Juntawong S, Charoenteeraboon J, Chansiri G, Tuntarawongsa T, Katewongsa P, Phaechamud T. Cream prepared from emulsifying polymer: effect of oil content, stirring intensity and mixing temperature. Res J Pharm Biol Chem Sci 2010;1:360-5.

33. Kartini K, Fitriani EW, Winarjo BM, Islamie R. Formulation and $\mathrm{pH}-$ physical stability evaluation of gel and cream of Plantago major Leaves Extract. Media Pharm Indonesiana 2017;1:174-80.

34. Bajaj S, Singla D, Sakhuja N. Stability testing of pharmaceutical products. J Appl Pharm Sci 2012;2:129-38. 
35. Chang RK, Raw A, Lionberger R, Yu L Generic development of topical dermatologic products: formulation development, process development, and testing of topical dermatologic products. AAPS J 2013;15:41-52.

36. Cosmetics Europe. Guidelines on stability testing of cosmetics products. Available from: https://www.cosmeticseurope.eu/
Guidelines_on_Stability_Testing_of_Cosmetics_C. [Last accessed on 29 Aug 2018]

37. Tozettoa JT, Tozettoa AT, Hoshinoa BT, Andrighettia CR, Ribeiro EB, Cavalheirob L, et al. Extract of Punica granatum L.: an alternative to BHT as an antioxidant in semisolid emulsified systems, Quim. Nova 2017;40:97-104. 